Article

\title{
Changing Energy Requirements in the Mediterranean Under Changing Climatic Conditions
}

\author{
Christos Giannakopoulos ${ }^{1, *}$, Panos Hadjinicolaou ${ }^{2}$, Christos Zerefos ${ }^{3}$ and \\ George Demosthenous ${ }^{4}$
}

1 Institute for Environmental Research and Sustainable Development, National Observatory of Athens, Athens 15236, Greece

2 Energy, Environment and Water Research Center, The Cyprus Institute, Nicosia 1061, Cyprus; E-Mail: p.hadjinicolaou@cyi.ac.cy

3 National Observatory of Athens, Athens 11851, Greece; E-Mail: zerefos@geol.uoa.gr

4 Frederick University, Nicosia 1036, Cyprus; E-Mail: eng.dg@fit.ac.cy

* Author to whom correspondence should be addressed; E-Mail: cgiannak@meteo.noa.gr; Tel.: +30-210-810-9128; Fax: +30-210-810-3236.

Received: 10 September 2009 / Accepted: 25 September 2009 / Published: 30 September 2009

\begin{abstract}
This study investigates the impacts of climate change on energy requirements in the Mediterranean. Energy requirements, especially for space heating and cooling, are closely linked to several weather variables, mainly air temperature. The analysis is based on daily temperature outputs from several regional climate models run at a resolution of $25 \mathrm{~km} \times 25 \mathrm{~km}$ in the framework of EU project ENSEMBLES using the A1B emissions scenario. The impacts of changes in temperature on energy requirements are investigated using the concept of degree days, defined as the difference of mean air temperature from a base temperature. Base temperature should be chosen to coincide with the minimum energy consumption. In this way, changes in heating and cooling requirements between the reference and the future period are calculated and areas about to undergo large changes identified. These changes are calculated between a 30-year reference period 1961-1990 and a near future period 2021-2050 taking the ensemble mean of all regional climate models. The near-term future has been chosen instead of the frequently used end-of-the-century period to assist policy makers in their planning. In general, a decrease in energy requirements is projected under future milder winters and an increase under hotter summers.
\end{abstract}


Keywords: energy demand; heating; cooling; regional climate models; climate change; Mediterranean

\section{Introduction}

Energy demand is linked to climatic conditions [1] and the relationship of energy demand and temperature is non-linear. The variability of ambient air temperature is closely linked to energy consumption, whose maximum values correlate with the extreme values of air temperature (maximum or minimum). In the Mediterranean region, during January, the maximum values of energy consumption are related to the appearance of the lowest temperatures. During the transient season of March-April, energy consumption levels remain fairly stable until about May though air temperatures are generally rising. From about mid-May onwards, and throughout the summer period, any increase in air temperature translates to an increase in energy consumption, mainly due to the extensive use of air conditioning. The exception is August since most people in the Mediterranean region tend to take their summer holidays. Another transient period exists in the months of September and October where energy demand and consumption remain fairly uniform. This transient period is followed by a period of continually increasing energy demand with a peak before the Christmas festive period. Therefore, with warmer weather decreased demand should be expected in winter and increased demand in summer [1,2]. Moreover, in the summer, the effect of higher temperatures is likely to be considerably greater on peak energy demand than on net demand, suggesting that there will be a need to install additional generating capacity over and above that needed to cater for underlying economic growth. The purpose of this study is to investigate the impacts of climate change on energy requirements in the Mediterranean using daily temperature outputs from several regional climate models.

\section{Methodology}

Since the energy use-temperature relationship is non-linear, with two branches relating to requirements for heating and cooling, it is convenient to separate these two branches. The easiest way to achieve this is to use the idea of Degree-Days, which are defined as the difference $\left(\right.$ in $\left.{ }^{\circ} \mathrm{C}\right)$ of mean daily temperature from a base temperature.

Base temperature should be the temperature where energy consumption is at its minimum. If this temperature is chosen, then the degree-day index is positive in the summer branch and negative in the winter branch. Instead of having both positive and negative values for this index, the definition of two indices is used: heating (HDD) and cooling degree days (CDD).

For the calculation of the HDD and CDD indices, the following equations were used:

$$
\begin{aligned}
& \mathrm{HDD}_{\mathrm{i}}=\max \left(\mathrm{T}^{*}-\mathrm{T}_{\mathrm{i}}, 0\right) \\
& \mathrm{CDD}_{\mathrm{i}}=\max \left(\mathrm{T}_{\mathrm{i}}-\mathrm{T}^{* *}, 0\right)
\end{aligned}
$$

where $\mathrm{T}^{*}$ and $\mathrm{T}^{* *}$ are the base temperatures for HDD and CDD respectively, which can be either the same or different and $\mathrm{T}_{\mathrm{i}}$ is the mean daily temperature on day $\mathrm{i}$. In this study, temperature estimates are based on outputs from regional climate models representing present day and future conditions. 
Daily values of HDDi (CDDi) are typically cumulated over a specified period (annual or seasonal) to provide an indication of the severity of winter (summer) conditions at a particular location in terms of the outdoor dry bulb air temperature, which in turn offers a guide to the likely aggregate energy demand for sensible heating (cooling) during that period. Beenstock et al. [3] defined the HDD for Israel by taking $\mathrm{T}^{*}=10{ }^{\circ} \mathrm{C}$ and the $\mathrm{CDD}$ by selecting $\mathrm{T}^{* *}=25^{\circ} \mathrm{C}$. Within these two limits a "comfort zone" could be established, in which no heating or cooling is required. Kadioğlu et al. [4] used different base levels $15{ }^{\circ} \mathrm{C}$ and $24{ }^{\circ} \mathrm{C}$ for calculations of HDD and CDD in Turkey, respectively. Cartalis et al. [5], in their study for of climate changes in the southeastern Mediterranean, used the threshold values of $15.5^{\circ} \mathrm{C}$ and $18{ }^{\circ} \mathrm{C}$ for HDD and CDD calculations, respectively. For Greece, and only for the specific calculation of the CDDs for the four summer months (June to September), base temperatures of $25{ }^{\circ} \mathrm{C}$ and $28{ }^{\circ} \mathrm{C}$ were used [6]. It is clear that different studies use varying levels of base temperature for cooling and heating demands. In the present study we use $15{ }^{\circ} \mathrm{C}$ for the calculation of HDDs and $25{ }^{\circ} \mathrm{C}$ for the calculation of CDDs, as used in the study of Giannakopoulos [7].

Daily output data from six regional climate models (RCMs) developed at KNMI (Netherlands), CNRM (France), ETHZ (Switzerland), MPI (Germany), METO (UK) and METNO (Norway) within the framework of the EU ENSEMBLES project have been used [www.ensembles-eu.org]. All models have a horizontal resolution of $25 \mathrm{~km} \times 25 \mathrm{~km}$ and use the A1B greenhouse gases emissions scenario [8]. The control run represents the base period 1961-1990 and has been used here as reference for comparison with the future period 2021-2050. The future period has been chosen specifically for the needs of policy makers to assist their planning in the near future, instead of the end of the $21^{\text {st }}$ century as frequently used in climate impact studies [7]. Note that the previous study of Giannakopoulos [7] made use of projections from a only a single, coarse resolution global climate model. The plots in the subsequent sections are drawn for the ensembles mean of the 6 ENSEMBLES RCMs and indicate changes in the cumulative numbers of CDDs and HDDs between the future period 2021-2050 and the control 1961-1990. Computations were carried out for all years of each 30-year averaging period and then averaged. To determine whether the climate change signal depicted by the 6 RCMs is a robust one, we have also plotted the standard deviation of the changes in the annual plots as a measure of the inter-model spread.

\section{Cooling Energy Requirements}

Figure 1 shows the seasonal changes in CDDs between future and control periods. Autumn and summer have been chosen as these seasons present the most considerable changes. As expected the main contribution is from summer with less marked changes occurring in autumn. During summer significant changes are evident all over the region but most notably over continental parts of Spain, Southern Italy, Greece, Turkey, Cyprus and North Africa. In fall, it is worth noting the increasing needs for cooling over Southern Spain and the Southeastern parts of the Mediterranean (Cyprus region).

Figure 2 presents the changes in annual cooling degree days between future and control periods as well as the standard deviation of the changes among the RCMs utilized. Over the year, more cooling will in general be required. The increase in cooling requirements will be larger over Southern Spain, 
the Eastern parts of Greece, Western Turkey and more so over Cyprus/North Africa. Smaller changes are expected in Sardinia, Corsica and the Aegean islands. These changes are a robust feature among the RCMs used, since the standard deviation is much smaller than the changes themselves. Moreover, the cooling demand increases are not expected to be uniform from year to year. As Fronzek and Carter [9] have indicated inter-annual variability also increases in the future climate, leading to more variable cooling demand from year-to-year.

Figure 1. Changes in autumn (top) and summer (bottom) cumulative CDD between future and control period.
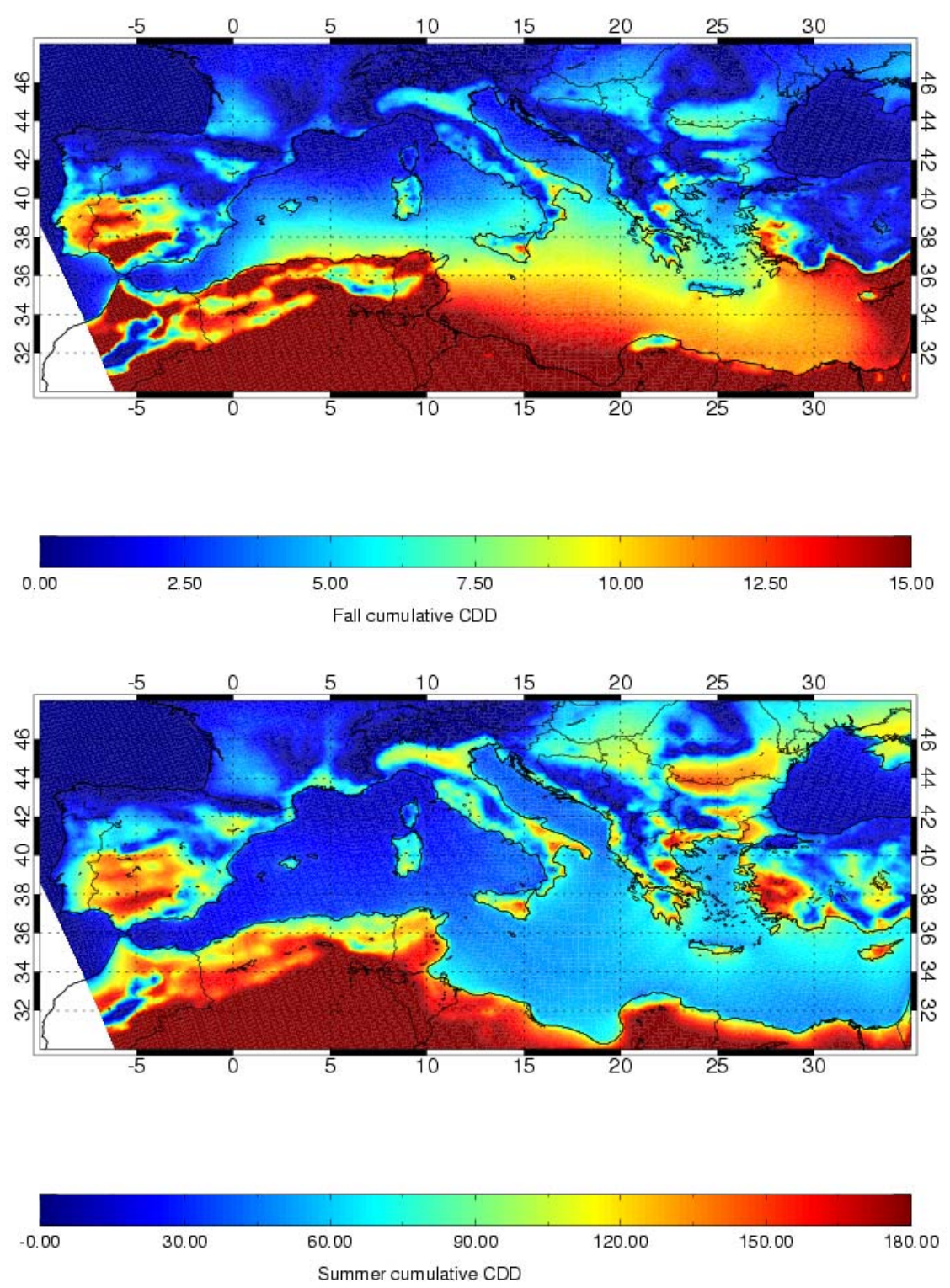
Figure 2. Changes in annual cumulative CDD between future and control period (top) and standard deviation of the changes (bottom).
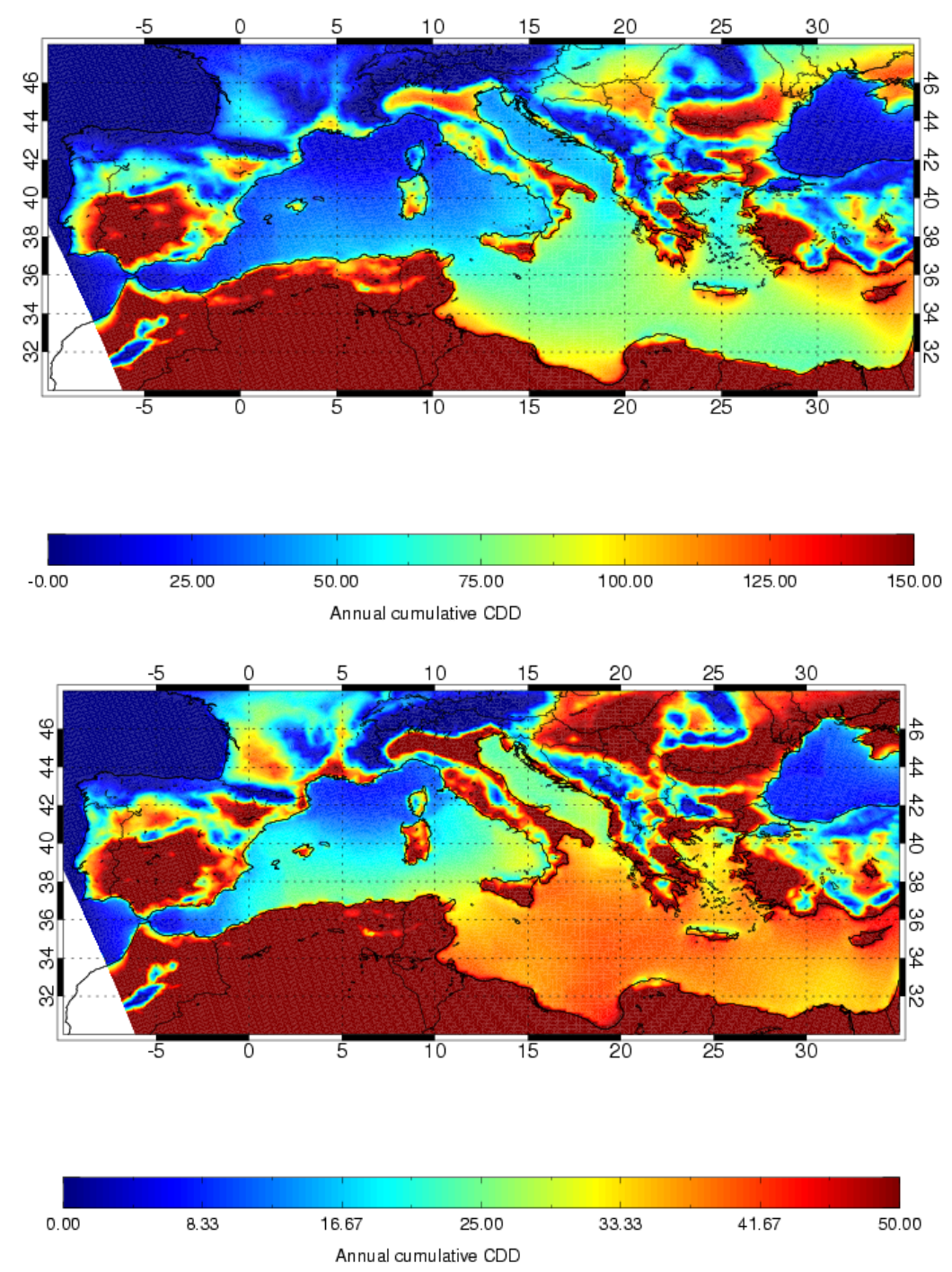

Figure 3 presents another view on the increase of cooling demands by showing the changes in the number of days needed to cool more than $5{ }^{\circ} \mathrm{C}$ between the two periods as well as the standard deviation of these changes. It is clear that in the North Africa more than one additional month of heavy cooling will be required whereas over parts of Southern Spain and Italy, Eastern Greece, Western Turkey and Cyprus 15 more days of heavy cooling will be needed. Elsewhere increases of less than 15 days are evident for the near future period of 2021-2050. For comparison, Giannakopoulos [7] and Alcamo et al. [10] state that an additional two to three weeks along the Mediterranean coast will require cooling whereas inland up to five more weeks of cooling will be needed by the end of the $21^{\text {st }}$ century, i.e., by 2071-2100. These changes present a robust signal among the models since the standard deviation among the RCMs is smaller than the changes. 
Figure 3. Changes in the number of days with high CDD (CDD $>5$ ) between future and control period (top) and standard deviation of the changes (bottom).
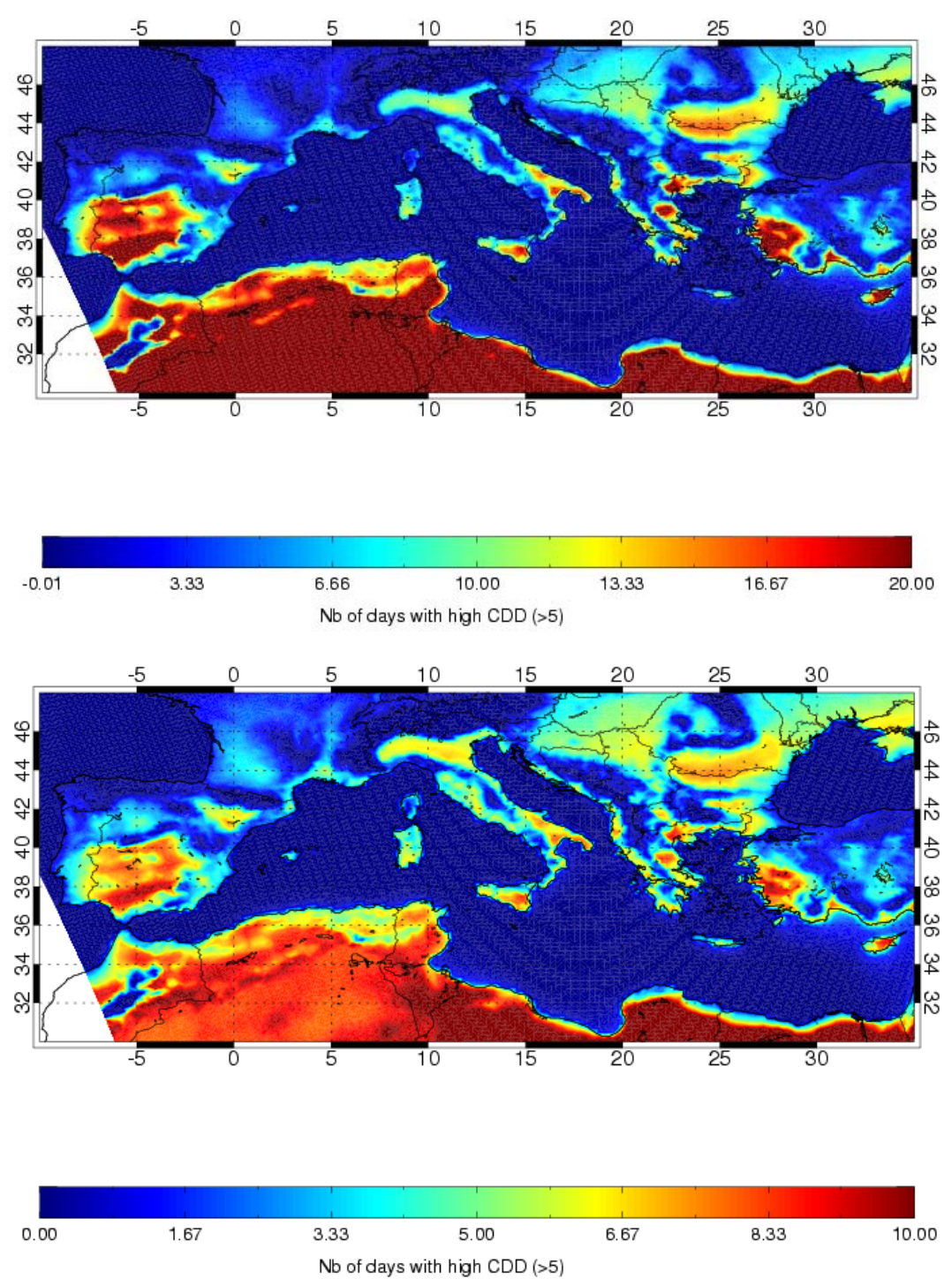

\section{Heating Energy Requirements}

Figure 4 presents the seasonal changes in HDDs. Large decreases in heating requirements are apparent in all seasons, especially spring and winter. The largest decrease is apparent, as expected in winter, with spring following. These changes are evident in continental parts of the region and thus are much less pronounced over islands.

Figure 5 presents the changes in annual heating degree days between future and control periods as well as the standard deviation of the changes among the RCMs utilized. Over the year, less heating will be required especially over continental parts of Northern Spain, central Italy, Greece and Turkey. Smaller changes are apparent in the North Africa and coastal areas and islands, due to the fact that these areas already experience a mild climate at the present day. The pattern of changes can again be interpreted as robust since the absolute changes are much larger than the standard deviation. 
Figure 6 presents another view on the decrease of heating demands by showing the changes in the number of days needed to heat more than $5{ }^{\circ} \mathrm{C}$ between the two periods as well as the standard deviation of these changes. As shown in Figure 6, the decrease in the number of days that require heating more than $5{ }^{\circ} \mathrm{C}$ varies from about 20 days inland to just one week or less in the islands of the Mediterranean sea by 2021-2050. For comparison, Giannakopoulos et al. [7] and Alcamo et al. [10] state that around the Mediterranean two to three fewer weeks will require heating by the end of the $21^{\text {st }}$ century, i.e., by 2071-2100. Again, the robustness of the pattern of changes is confirmed by the smaller standard deviation.

Figure 4. Changes in spring (top) and winter (bottom) cumulative HDD between future and control period.
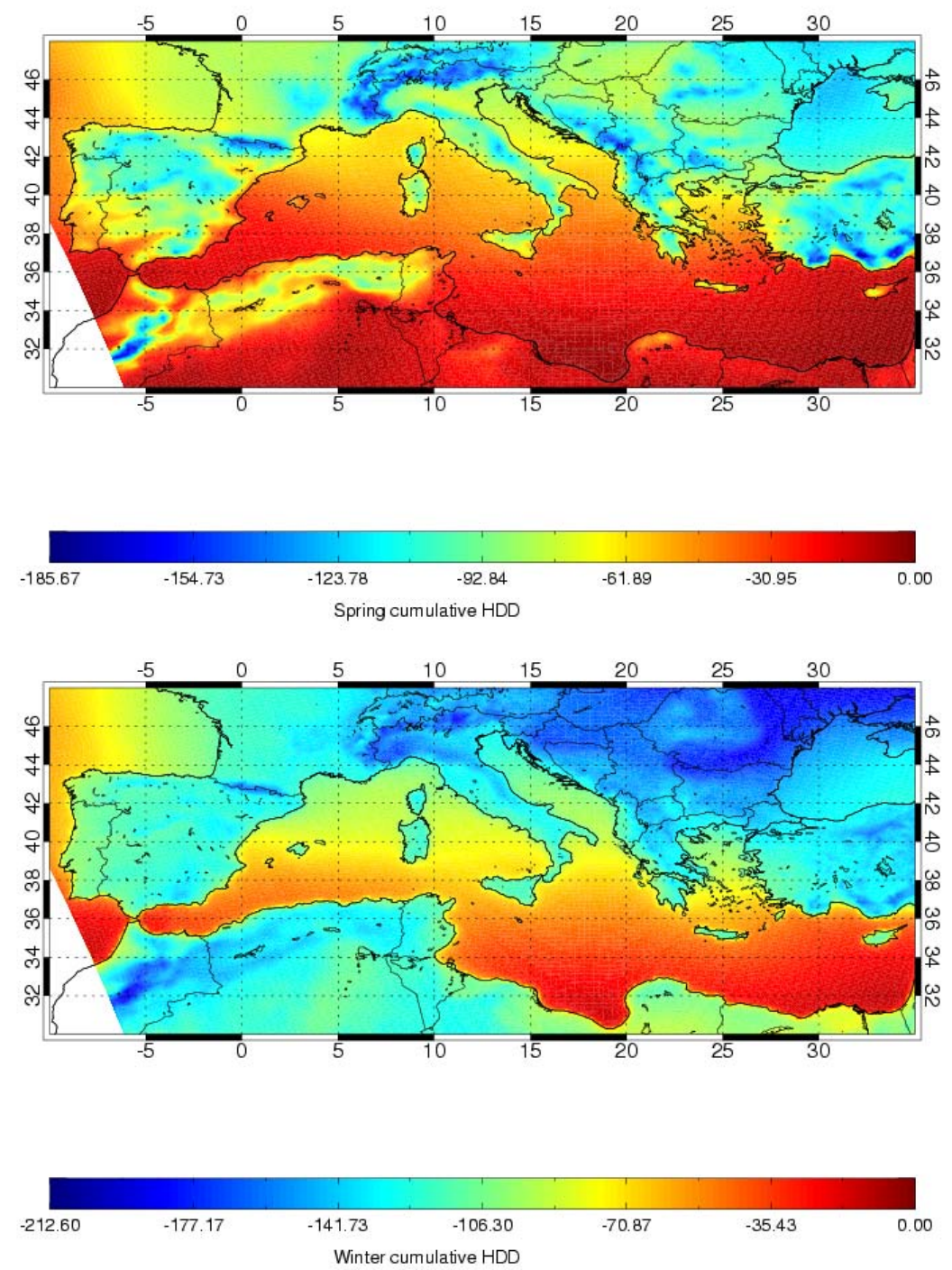
Figure 5. Changes in annual cumulative HDD between future and control period (top) and standard deviation of the changes (bottom).
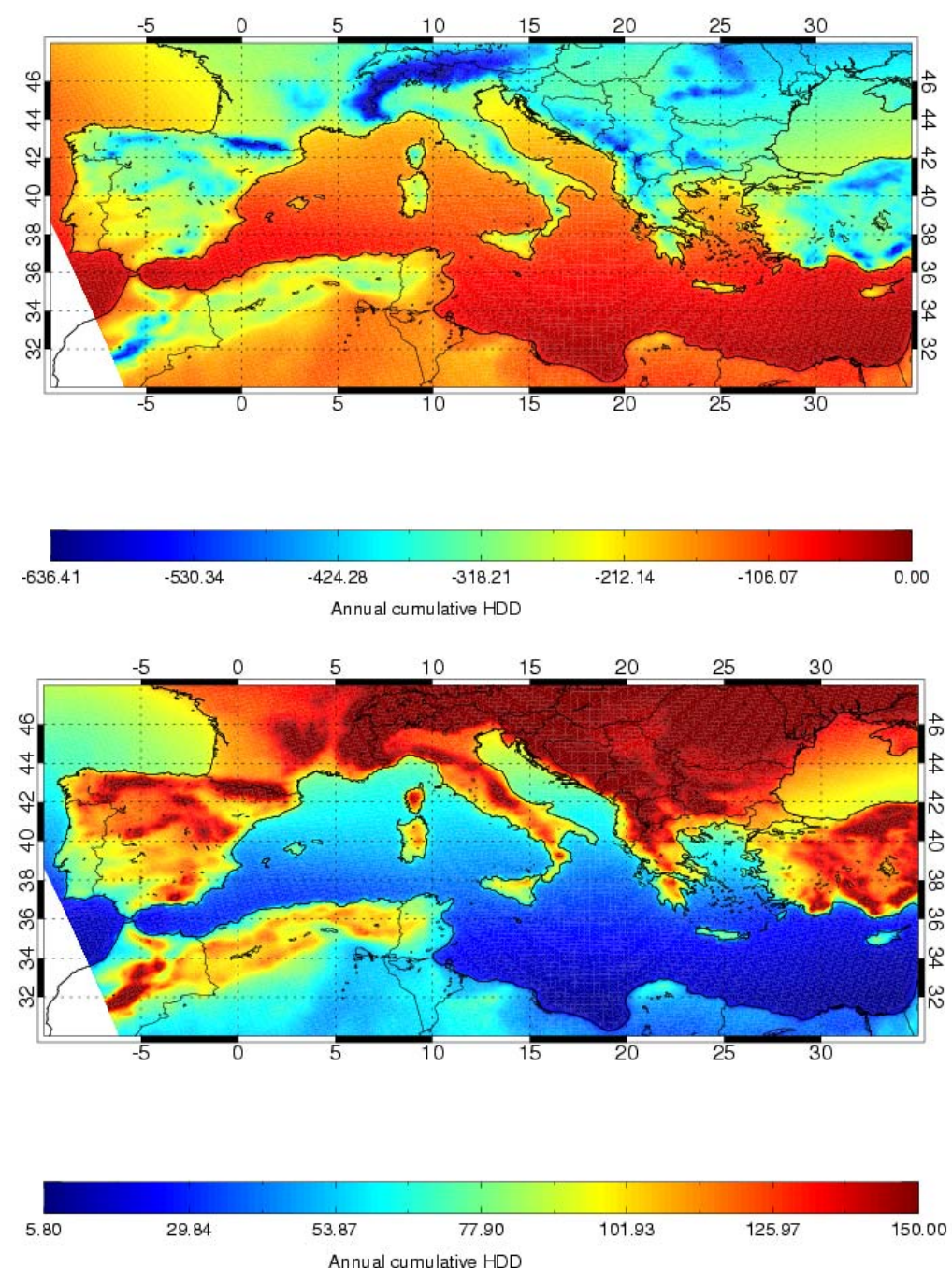

Figure 6. Changes in the number of days with high HDD $(\mathrm{HDD}>5)$ between future and control period (top) and standard deviation of the changes (bottom).
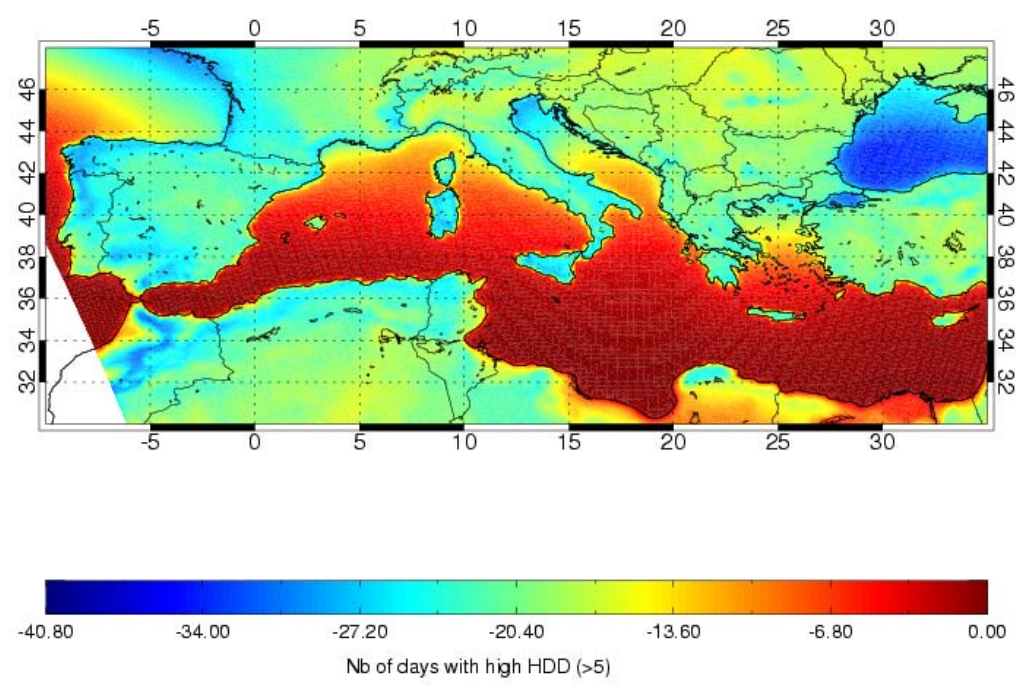
Figure 6. Cont.
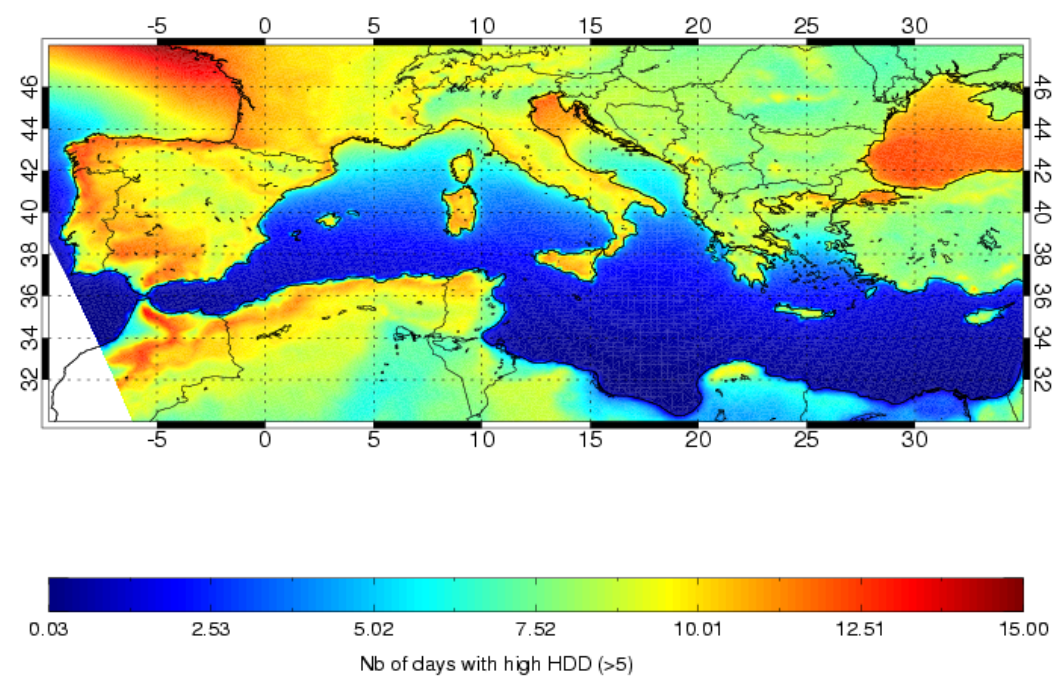

\section{Conclusions and Implications for Power Usage}

Continental parts of the Mediterranean region are likely to experience the most significant changes both in heating and cooling energy requirements. More specifically, large decreases in heating demand are evident especially during winter and spring. Conversely, large increases in cooling energy requirements are apparent for summer and less so for autumn, especially in North Africa and the southeastern parts of the region. The peak in cooling energy demand hence falls in the dry season. A low water supply reduces energy production from hydroelectric plants, as well as from conventional power plants, which require water for cooling and for driving the turbines [11]. As a result, energy demands may not be able to be met in the warm period of the year. Additional capacity may need to be installed unless adaptation/mitigation strategies or stricter construction regulations to improve insulation of the buildings are to be put into place. Such measures tackling building codes could help minimize increases in energy demand under climate change. On the other hand, conditions for energy production using other renewables, such as solar and wind energy [12], may improve under climate change.

It should be noted that climate projections and hence impacts are associated with uncertainties. Uncertainties begin with different socio-economic assumptions that affect projections of greenhouse gas emissions, and flow through differing potential emission scenarios and ranges of greenhouse gas concentrations, radiative forcing, and climate system responses and feedbacks. These in turn affect the estimation of the range of potential impacts, in our case the impacts on cooling and heating demands. However, taking an ensemble mean of several RCMs and presenting the standard deviation as a measure of inter-model spread, is certainly a step forward towards reducing uncertainties associated with climatic projections. It should also be noted that temperature is not the only variable linked with energy demand levels. Other primitive independent variables, such as relative humidity, cloudiness, rainfall, solar radiation and wind speed $[13,14]$, and derived variables including latent enthalpy-days, temperature-humidity index, indoor apparent temperature, cooling radiation-days and clothing insulation units $[15,16]$ have also been used by other researchers to address the complex problem of 
energy demand characteristics. Therefore a future study could focus, apart from temperature, on a combination of other variables affecting energy demand as well.

\section{Acknowledgements}

This work was partly supported by the project CLIMA2070, funded by the Research Promotion Foundation Cyprus and the CIMME project funded by EEWRC at the Cyprus Institute. The authors also gratefully acknowledge the EU FP6 project ENSEMBLES (www.ensembles-eu.org) for financial support and RCM data provision.

\section{References and Notes}

1. Giannakopoulos, C.; Psiloglou, B. Trends in energy load demand for Athens, Greece: weather and non-weather related factors. Climate Res. 2006, 13, 97-108.

2. Valor, E.; Meneu, V; Caselles, V. Daily air temperature and electricity load in Spain. J. Appl. Meteor. 2001, 40, 1413-1421.

3. Beenstock, M.; Goldin, E.; Nabot, D. The demand for electricity in Israel. Energy Econ. 1999, 21, $168-183$.

4. Kadioğlu, M.; Şen, Z.; Gültekin, L. Variations and trends in Turkish seasonal heating and cooling degree-days. Climatic Change 2001, 49, 209-223.

5. Cartalis, C.; Synodinou, A.; Proedrou, M.; Tsangrassoulis, A.; Santamouris, M. Modifications in energy demand in urban areas as a result of climate changes: an assessment for the southeast Mediterranean region. Energ. Conv. Manage. 2001, 42, 1647-1656.

6. Tselepidaki, I.; Santamouris, M.; Asimakopoulos, D.N.; Kontoyiannidis, S. On the variability of cooling degree-days in an urban environment: application to Athens, Greece. Energ. Bldg. 1994, 21, 93-99.

7. Giannakopoulos, C.; LeSager, P.; Bindi, M.; Moriondo, M.; Kostopoulou, E.; Goodess, C.M. Climatic changes and associated impacts in the Mediterranean resulting from a $2{ }^{\circ} \mathrm{C}$ global warming. Global Planet. Change 2009, 68, 209-224.

8. Nakicenovic, N.; Alcamo, J.; Davis, D.; de Vries, B.; Fenhann, J.; Gaffin, S.; Gregory, K.; Grubler, A.; Jung, T.Y.; Kram, T.; la Rovere, E.; Michaelis, L.; Mori, S.; Morita, T.; Pepper, W.; Pitcher, H.; Price, L.; Riahi, K.; Roehrl, A.; Rogner, H.; Sankovski, A.; Schlesinger, M.; Shukla, P.; Smith, S.; Swart, R.; van Rooijen, S.; Victor, N.; Dadi, Z. Special Report on Emissions Scenarios, Working Group III, Intergovernmental Panel on Climate Change (IPCC); Cambridge University: Cambridge, UK, 2000.

9. Fronzek, S; Carter, T.R. Assessing uncertainties in climate change impacts on resource potential for Europe based on projections from RCMs and GCMs. Climatic Change 2007, 81, 357-371.

10. Alcamo, J.; Moreno, J.M.; Nováky, B.; Bindi, M.; Corobov, R.; Devoy, R.J.N.; Giannakopoulos C.; Martin, E.; Olesen, J.E.; Shvidenko, A. Europe. Climate change 2007: impacts, adaptation and vulnerability. In Contribution of Working Group II to the Fourth Assessment Report of the Intergovernmental Panel on Climate Change (IPCC); Parry, M.L., Canziani, O.F., Palutikof, J.P., van der Linden, P.J., Hanson, C.E., Eds; Cambridge University: Cambridge, UK, 2007; pp. 541-580. 
11. Hoffmann, J.; Forbes, S.; Feeley, T. Estimating Freshwater Needs to Meet 2025 Electricity Generating Capacity Forecasts; National Energy Technology Laboratory, U.S. Department of Energy: Pittsburgh, PA, USA, June 2004; available online: http://www.netl.doe.gov/technologies/coalpower/ewr/pubs/Estimating\%20Freshwater\%20Needs\% 20to\%202025.pdf (accessed 25 September, 2009).

12. Leckebusch, G.C.; Ulbrich, U. On the relationship between cyclones and extreme windstorm events over Europe under climate change. Global Planet. Change 2004, 44, 181-193.

13. Sailor, D.J.; Muñoz, J.R. Sensitivity of electricity and natural gas consumption to climate in the U.S.A.-Methodology and results for eight states. Energy 1997, 22, 987-998.

14. Bard, E.A.; Nasr, G.E. On the relationship between electrical energy consumption and climate factors in Lebanon: co-integration and error-correction models. Int. J. Energy Res. 2001, 25, $1033-1042$.

15. Lam, J.C. Climatic and economic influences on residential electricity consumption. Energ. Conv. Manage. 1998, 39, 623-629.

16. Howden, S.; Crimp, S. Effect of climate and climate change on electricity demand in Australia. Proceedings of the MODSIM 2001, International Congress on Modelling and Simulation, Canberra, Australia, December 10-13, 2001.

(C) 2009 by the authors; licensee Molecular Diversity Preservation International, Basel, Switzerland. This article is an open-access article distributed under the terms and conditions of the Creative Commons Attribution license (http://creativecommons.org/licenses/by/3.0/). 